\title{
Measurement and Thermodynamics of Carbon Solubilities in Molten Si-Fe, Si-Ni, and Si-Cr-Fe Alloys at 2073 K
}

\author{
Sakiko KAWANISHI ${ }^{1 *}$ and Takeshi YOSHIKAWA ${ }^{21}$ \\ 1) Institute of Multidisciplinary Research for Advanced Materials, Tohoku University, 2-1-1, Katahira, Aoba-ku, Sendai, Miyagi, \\ 980-8577 Japan. \\ 2) Institute of Industrial Science, The University of Tokyo, 4-6-1 Komaba, Meguro-ku, Tokyo, 153-8505 Japan.
}

(Received on August 15, 2019; accepted on November 25, 2019; originally published in Tetsu-toHagané, Vol. 105, 2019, No. 3, pp. 389-394; J-STAGE Advance published date: March 18, 2020)

\begin{abstract}
The equilibrium phase relations of molten $\mathrm{Si}-\mathrm{Fe}, \mathrm{Si}-\mathrm{Ni}$, and $\mathrm{Si}-\mathrm{Fe}-\mathrm{Cr}$ alloys saturated with either silicon carbide $(\mathrm{SiC})$ or graphite, which are candidates for the solvent for rapid solution growth of $\mathrm{SiC}$, have been investigated. The measured carbon solubilities at $2073 \mathrm{~K}$ were 0.19-6.6 mol\% for the Si- $(24.1-70.1) \mathrm{mol} \%$ Fe, 0.061-5.2 mol\% for Si-(30.0-85.0) mol\% Ni, and 1.1-3.9 mol\% for Si-(50-x) mol\% Fe- $x$ mol\% Cr $(x=$ 10.4-40.1) alloys. A quasi-chemical model that assumes that the carbon atoms are introduced into the interstitial sites of the $\mathrm{Si}-\mathrm{Fe}, \mathrm{Si}-\mathrm{Ni}$, and $\mathrm{Si}-\mathrm{Fe}-\mathrm{Cr}$ solvents and obstruct the bonding between solvent atoms was used to evaluate the activity coefficient of carbon in each alloy. The estimation reproduced the trends of the measured carbon solubilities fairly well. However, the estimation using the sub-regular solution model often overestimated the carbon solubilities. Thus, the carbon behavior in molten silicontransition metal alloys is well described by the quasi-chemical model.
\end{abstract}

KEY WORDS: carbon solubility; thermodynamics; quasi-chemical model.

\section{Introduction}

The thermodynamic properties of carbon in molten alloys are indispensable for controlling the carbon concentration and formation of carbides in the alloys. The activity coefficient of carbon in molten iron has been measured in terms of the interaction parameters using the formalism proposed by Wagner. ${ }^{1)}$ The interaction parameters between carbon and the other components are known to show a periodic trend, similar to the interaction parameters of sulfur and oxygen. ${ }^{2-4)}$ The Wagner's formalism can be adopted for dilute solution, and hence it should be carefully used for high alloys. Miki et $a .^{5-8)}$ proposed a model based on Darken's quadratic formalism $^{9,10)}$ to express the activities of the components in iron- and nickel-based high alloys, and they evaluated their deoxidation equilibria. However, a thermodynamic model to express the activity of carbon in molten alloys for a wide composition range has not been proposed.

We have investigated the temperature and composition dependence of the carbon solubility in the molten $\mathrm{Si}-\mathrm{Cr}$ alloy. ${ }^{11)}$ Estimation by the sub-regular solution model using the interaction coefficients of the $\mathrm{Si}-\mathrm{Cr}, \mathrm{Si}-\mathrm{C}$, and $\mathrm{Cr}-\mathrm{C}$ systems gave larger carbon solubilities than the measured values because of underestimation of the carbon activity

\footnotetext{
* Corresponding author: E-mail: s-kawa@tohoku.ac.jp
}

coefficients. The molten $\mathrm{Si}-\mathrm{Cr}$ alloy shows exothermic mixing, leading to a repulsive interaction between carbon and the solvent atoms in terms of the substitutional solution in the sub-regular solution model. A quasi-chemical model ${ }^{12)}$ involving a larger repulsive interaction for carbon was also used (see Section 2.2), which allowed reasonably good prediction of the measured carbon activity coefficients in wide temperature and composition ranges. However, the applicability of the quasi-chemical model to other alloy systems is still unclear.

In this study, to further investigate the thermodynamic behavior of carbon in molten silicon-transition metal alloys, the carbon solubilities in molten $\mathrm{Si}-\mathrm{Fe}, \mathrm{Si}-\mathrm{Ni}$, and $\mathrm{Si}-\mathrm{Fe}-\mathrm{Cr}$ alloys at $\mathrm{SiC}$ or graphite saturation were measured at $2073 \mathrm{~K}$. In addition, the equilibrium phase relations were evaluated by both the sub-regular solution and quasichemical models for the liquid phase to determine a suitable model for estimation of the carbon solubility in such alloys.

\section{Methodology}

\subsection{Measurement of the Carbon Solubilities in the Molten Alloys}

The solubility measurements of the $\mathrm{Si}-(24.1-70.1)$ $\mathrm{mol} \% \mathrm{Fe}, \mathrm{Si}-(30.0-85.0) \mathrm{mol} \% \mathrm{Ni}$, and $\mathrm{Si}-(50-x) \mathrm{mol} \%$ $\mathrm{Fe}-x \mathrm{~mol} \% \mathrm{Cr}(x=10.4-40.1)$ alloys at $\mathrm{SiC}$ or graphite 
saturation were performed by using an induction furnace $(280 \mathrm{kHz})$. A schematic illustration of the experimental apparatus is shown in Fig. 1. For the $\mathrm{Si}-\mathrm{Fe}$ and $\mathrm{Si}-\mathrm{Cr}-\mathrm{Fe}$ systems, a piece of silicon lump $(6 \mathrm{~N})$ and the additive metals (chromium chip (99.9\%) and iron wire (99.5\%)) were weighed to achieve the target composition. The $\mathrm{Si}-\mathrm{Ni}$ alloy was preliminarily prepared by melting a piece of silicon lump and nickel wire $(99.99 \%)$ on an $\mathrm{Al}_{2} \mathrm{O}_{3}$ substrate under vacuum at lower than $0.1 \mathrm{~Pa}$. The metal material or the prepared alloy $(0.1 \mathrm{~g}$ in total) was then placed on either a $4 \mathrm{H}-\mathrm{SiC}$ single crystal $(11 \mathrm{~mm} \times 10 \mathrm{~mm} \times 0.35 \mathrm{~mm}$ thick $)$ or a high-density graphite substrate, which was fixed inside the graphite container. Here, the material of the substrate

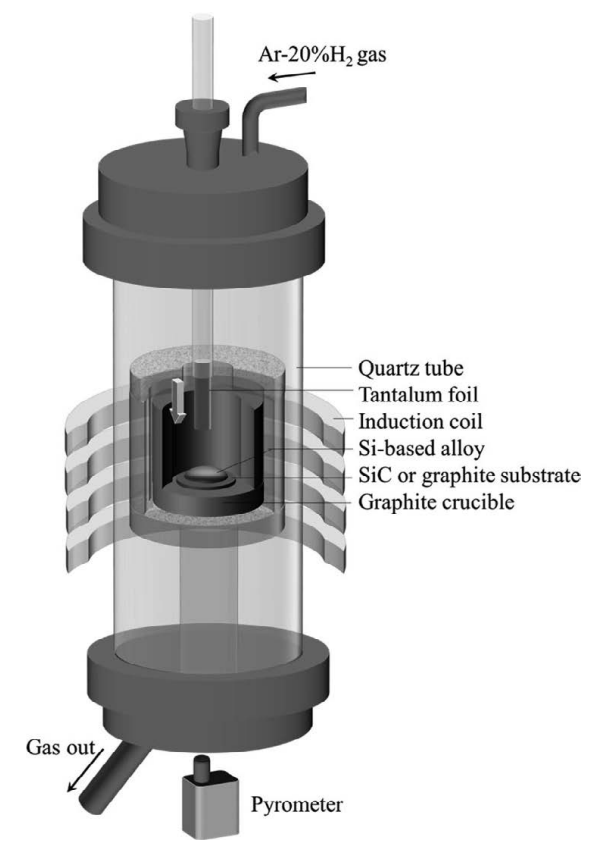

Fig. 1. Schematic illustration of the experimental apparatus used for measurement of the carbon solubilities in the molten Si-based alloys. (either $\mathrm{SiC}$ or graphite) was carefully selected to satisfy the saturation phase of the alloy to suppress the excess dissolution of carbon caused by contact with the metastable phase. In addition, selection of the substrate is indispensable to avoid loss of silicon (or carbon) from the alloy by formation of $\mathrm{SiC}$ (or graphite) at the interface between the alloy and the graphite (or $\mathrm{SiC}$ ) substrate.

After evacuation of the quartz reaction tube under $0.1 \mathrm{~Pa}$, the sample was heated to $1273 \mathrm{~K}$, where the temperature of the substrate was controlled by measuring the temperature using a single color pyrometer through the opening at the bottom of the graphite crucible. $\mathrm{Ar}-20 \% \mathrm{H}_{2}$ gas, whose moisture and oxygen were removed by gas purification columns, was then introduced into the reaction tube, and the sample was heated to $2073 \mathrm{~K}$ with melting of the droplet. The droplet was maintained for more than $10 \mathrm{~min}$, which was preliminarily determined to ensure that it was saturated with either $\mathrm{SiC}$ or graphite, and the alloy droplet was sucked by contact with rolled tantalum foil. The weight of the collected alloy was calculated from the weight gain of the tantalum foil. The alloy was analyzed by the combustion-infrared absorption method using a CS-400 analyzer (LECO Co.) together with the tantalum foil and the carbon concentration in the collected alloy was determined.

\subsection{Thermodynamic Models}

2.2.1. Sub-regular Solution Model

To evaluate the liquid phase by the sub-regular solution model, the contributions of the binary systems were summed to obtain the excess Gibbs free energy of the liquid phase with expression of Redlich-Kister type polynomial and the activity coefficient of carbon was derived:

$$
\Delta G_{\text {binary, liq }}^{\mathrm{ex}}=X_{i} X_{j} L_{i-j, \text { liq }}=X_{i} X_{j} \sum_{m=0}^{n}\left\{L_{i-j, \text { liq }}^{m}(T)\left(X_{i}-X_{j}\right)^{m}\right\}
$$

where $X_{i}$ and $X_{j}$ are the mole fractions of components $i$ and $j$, and $L_{i-j, \text { liq }}$ is the interaction parameter between components

Table 1. Sub-regular solution parameters describing the excess properties of the liquid phase for each binary system.

\begin{tabular}{|c|c|c|}
\hline System & Sub-regular solution parameter, $L_{\mathrm{i}-\mathrm{j}}^{n} / \mathrm{J} \mathrm{mol}^{-1}$ & References \\
\hline $\mathrm{C}-\mathrm{Cr}$ & $L_{\mathrm{C}-\mathrm{Cr}}^{0}=-127957-7.6695 T, L_{\mathrm{C}-\mathrm{Cr}}^{1}=79574, L_{\mathrm{C}-\mathrm{Cr}}^{2}=86315$ & Teng et $a .^{13)}$ \\
\hline $\mathrm{C}-\mathrm{Fe}$ & $L_{\mathrm{C}-\mathrm{Fe}}^{0}=-124320+28.5 T, L_{\mathrm{C}-\mathrm{Fe}}^{1}=19300, L_{\mathrm{C}-\mathrm{Fe}}^{2}=49260-19 T$ & Gustafson $^{14)}$ \\
\hline $\mathrm{C}-\mathrm{Ni}$ & $L_{\mathrm{C}-\mathrm{Ni}}^{0}=-111479+35.2685 T$ & Lee $^{15)}$ \\
\hline $\mathrm{C}-\mathrm{Si}$ & $L_{\mathrm{C}-\mathrm{Si}}^{0}=8700$ & Kawanishi et al. ${ }^{16)}$ \\
\hline $\mathrm{Cr}-\mathrm{Fe}$ & $L_{\mathrm{Cr}-\mathrm{Fe}}^{0}=-17737+7.9965467, L_{\mathrm{Cr}-\mathrm{Fe}}^{1}=-1331$ & Lee $^{17)}$ \\
\hline $\mathrm{Cr}-\mathrm{Si}$ & $\begin{array}{l}L_{\mathrm{Cr}-\mathrm{Si}}^{0}=-19216.57+16.11445 T \\
L_{\mathrm{Cr}-\mathrm{Si}}^{1}=-47614.70+12.17363 T\end{array}$ & Coughanowr et al. ${ }^{18)}$ \\
\hline $\mathrm{Fe}-\mathrm{Si}$ & $\begin{array}{l}L_{\mathrm{Fe}-\mathrm{Si}}^{0}=-151127.73+29.125 T \\
L_{\mathrm{Fe}-\mathrm{Si}}^{1}=-33882.38-2.5015 T \\
L_{\mathrm{Fe}-\mathrm{Si}}^{2}=33954.71-11.2555 T \\
L_{\mathrm{Fe}-\mathrm{Si}}^{3}=21289.56-0.865 T\end{array}$ & Hultgren et al. ${ }^{19)}$ \\
\hline $\mathrm{Ni}-\mathrm{Si}$ & $\begin{array}{l}L_{\mathrm{Ni}-\mathrm{Si}}^{0}=-205180+33.4 T \\
L_{\mathrm{Ni}-\mathrm{Si}}^{1}=-114200+20.34 T \\
L_{\mathrm{Ni}-\mathrm{Si}}^{2}=0, L_{\mathrm{Ni}-\mathrm{Si}}^{3}=-116640-53.87 T\end{array}$ & Du et $a l .{ }^{20)}$ \\
\hline
\end{tabular}


$i$ and $j$ in the liquid phase. The $L_{i-j, \text { liq }}$ value for each binary system is given in Table 1. ${ }^{13-20)}$

The carbon solubilities in the alloys at saturation with either $\mathrm{SiC}$ or graphite were estimated according to the reaction of $\mathrm{SiC}$ formation

$$
\begin{aligned}
& \operatorname{Si}(1)+C(1)=\operatorname{SiC}(s) \\
& \Delta G_{(2)}^{\circ}=-233100+61.01 T^{21,22)} \\
& (1686<T / \mathrm{K}<2000) \quad(\mathrm{J} / \mathrm{mol})
\end{aligned}
$$

or dissolution of graphite

$$
\begin{aligned}
& \mathrm{C}(\mathrm{l})=\mathrm{C} \text { (graphite) } \\
& \Delta G_{(3)}^{\circ}=-117369+24.63 T^{21)} \\
& (298.15<T / \mathrm{K}<6000) \quad(\mathrm{J} / \mathrm{mol})
\end{aligned}
$$

with the standard Gibbs energy changes ${ }^{21,22)}$

$$
\begin{gathered}
\Delta G_{(2)}^{\circ}=-R T \ln \frac{a_{\mathrm{SiC}}}{a_{\mathrm{Si}} a_{\mathrm{C}}}=R T \ln a_{\mathrm{Si}} \gamma_{\mathrm{C}} X_{\mathrm{C}}, \\
\Delta G_{(3)}^{\circ}=-R T \ln \frac{a_{\text {graphite }}}{a_{\mathrm{C}}}=R T \ln \gamma_{\mathrm{C}} X_{\mathrm{C}},
\end{gathered}
$$

using the activity of silicon and the activity coefficient of carbon obtained from Eq. (1). This estimation was performed using the thermodynamic calculation software FactSage 6.4.

\subsubsection{Quasi-chemical Model}

To evaluate the liquid phase by the quasi-chemical model, silicon, chromium, iron, and nickel were treated as solvent atoms at substitutional sites, while carbon was assumed to be a solute atom at an interstitial site by considering the difference in their atomic radii (Table 2). ${ }^{23-26)}$ The interstitial behavior of carbon in the alloy has been determined by high-temperature $\mathrm{X}$-ray diffraction analysis of the $\mathrm{Fe}-\mathrm{C}$ alloy. ${ }^{23)}$ Jacob and Alcock ${ }^{12)}$ proposed a model that assumes that the bonds between the solute and solvent atoms break some of the solvent-solvent bonds. In their model, the activity coefficient of the solute carbon at infinite dilution $\gamma_{\mathrm{C}}^{0}$ is

\begin{tabular}{|c|c|c|c|}
\hline Element & $\begin{array}{c}\text { Nearest neighbor } \\
\text { distance }(\AA)\end{array}$ & $\begin{array}{c}\text { Temperature } \\
(\mathrm{K})\end{array}$ & References \\
\hline $\mathrm{C}$ & $1.32 *$ & & Waseda et al. ${ }^{23)}$ \\
\hline $\mathrm{Si}$ & 2.48 & 1687 & Higuchi et al. ${ }^{24)}$ \\
\hline $\mathrm{Fe}$ & 2.55 & 1811 & Kita et $a l .{ }^{25)}$ \\
\hline $\mathrm{Ni}$ & 2.53 & 1873 & Waseda et al. ${ }^{26)}$ \\
\hline $\mathrm{Cr}$ & 2.58 & 2173 & Waseda et al. ${ }^{26)}$ \\
\hline
\end{tabular}
expressed by the following equation:

$$
\frac{1}{\left[\gamma_{\mathrm{C}}^{\circ}\right]^{1 / n}}=X_{i}\left\{\frac{\gamma_{i}^{t}}{\left[\gamma_{\mathrm{C}(i)}^{\circ}\right]^{1 / n}}\right\}+X_{j}\left\{\frac{\gamma_{j}^{t}}{\left[\gamma_{\mathrm{C}(j)}^{\circ}\right]^{1 / n}}\right\}+X_{k}\left\{\frac{\gamma_{k}^{t}}{\left[\gamma_{\mathrm{C}(k)}^{\circ}\right]^{1 / n}}\right\}
$$

where $\gamma_{i(j \text { or } k)}$ is the activity coefficient of the solvent component $i\left(j\right.$ or $k$ ) in the system without carbon and $\gamma_{\mathrm{C}(i)}^{\circ}$ is

Table 2. Nearest neighbor distance of each element for the pure liquid near the melting point.

* Estimated by assuming the ionic state in molten $\mathrm{Fe}-\mathrm{C}$ alloy. the activity coefficient of carbon at its infinite dilution in solvent $i$, both of which are derived from the thermodynamic properties of the binary systems listed in Table 1. $n$ is the coordination number of the solute atom bonding to the solvent atoms and $t$ is the fractional change of the coordination number of the solvent atoms caused by occupation of a solute atom at the interstitial site. Otsuka ${ }^{27)}$ investigated the combinations of $n=6$ and $t=1 / 3$, and $n=4$ and $t=1 / 2$, which were proposed by Saboungi et al. ${ }^{28)}$ and Jacob and Alcock, ${ }^{12)}$ respectively, and showed that the condition $n \times$ $t=2$ adequately describes the thermodynamic behavior of a non-metallic component, such as oxygen. Here, the liquid phase is generally close to a close-packed structure, such as face-centered cubic (FCC), ${ }^{29)}$ and the interstitial carbon atom in FCC iron occupies the center of the octahedral site, where the carbon atom has six bonds with iron. Therefore, the combination of $n=6$ and $t=1 / 3$ was used for all of the calculations in this study. We confirmed that the different combination $n=4$ and $t=1 / 2$ was not significantly different from $n=6$ and $t=1 / 3$ in terms of the calculated activity coefficient.

Similar to the case of the sub-regular solution model, the carbon solubility in the alloy at either $\mathrm{SiC}$ or graphite saturation was estimated from the standard Gibbs energy of SiC or graphite formation (Eqs. (4) and (5)). Note that the activity coefficient of carbon given by Eq. (6) is for its infinite dilution, and hence the value was assumed to be the same for the same ratio of the solvent concentrations.

\section{Results and Discussion}

\subsection{Carbon Solubilities in the $\mathrm{Si}-\mathrm{Fe}$ and $\mathrm{Si}-\mathrm{Ni}$ Alloys}

The measured carbon solubilities in the $\mathrm{Si}-\mathrm{Fe}$ and $\mathrm{Si}-\mathrm{Ni}$ alloys at $2073 \mathrm{~K}$ are plotted in Figs. 2 and 3. The change of the saturation phase from $\mathrm{SiC}$ to graphite by addition of metals occurred at about $60 \mathrm{~mol} \% \mathrm{Fe}$ for the $\mathrm{Si}-\mathrm{Fe}$ alloy and about $55 \mathrm{~mol} \% \mathrm{Ni}$ for the $\mathrm{Si}-\mathrm{Ni}$ alloy. The heats of mixing of the $\mathrm{Si}-\mathrm{Fe}, \mathrm{Si}-\mathrm{Ni}$, and $\mathrm{Si}-\mathrm{Cr}$ alloys at $2073 \mathrm{~K}$ calculated using thermodynamic data ${ }^{18-20)}$ are shown in Fig. 4. Both the $\mathrm{Si}-\mathrm{Fe}$ and $\mathrm{Si}-\mathrm{Ni}$ systems exhibit strong exothermic mixing. The activity coefficient of silicon is smaller for the

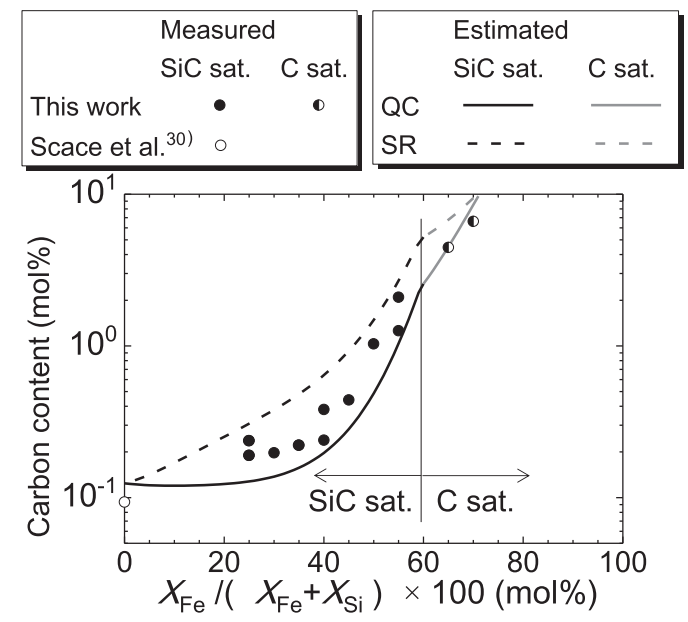

Fig. 2. Measured and estimated carbon solubilities in the $\mathrm{Si}-\mathrm{Fe}$ alloys at $2073 \mathrm{~K}$. QC: quasi-chemical model. SR: subregular solution model. The smallest value for each composition is assumed to be the carbon solubility. 

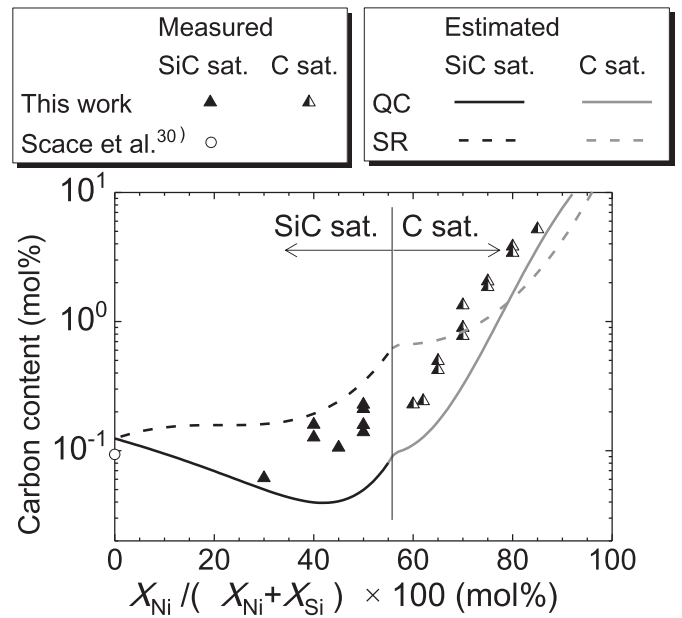

Fig. 3. Measured and estimated carbon solubilities in $\mathrm{Si}-\mathrm{Ni}$ alloys at $2073 \mathrm{~K}$. The smallest value for each composition is assumed to be the carbon solubility.

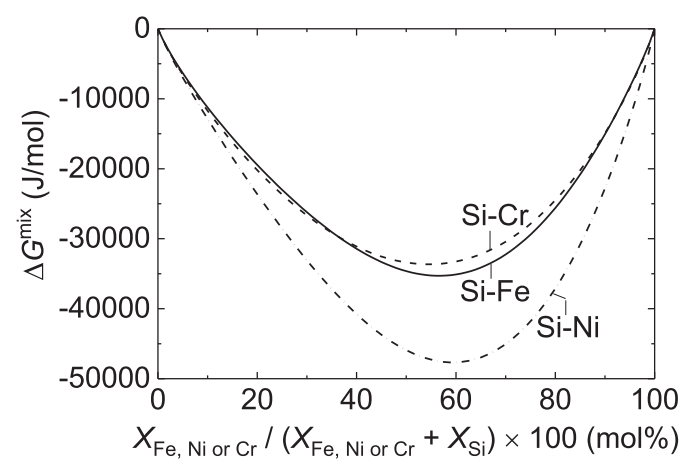

Fig. 4. Heats of mixing of the $\mathrm{Si}-\mathrm{Fe}, \mathrm{Si}-\mathrm{Ni}$, and $\mathrm{Si}-\mathrm{Cr}$ alloys at $2073 \mathrm{~K}$ calculated using thermodynamic data. ${ }^{18-20)}$

Si-Ni system because of its stronger exothermic tendency, leading to a narrower composition range for $\mathrm{SiC}$ saturation. The carbon contents in the low solubility region show some discrepancies, which may come from the excess content of carbon because of the fine $\mathrm{SiC}$ inclusions in the alloy. Therefore, the minimum values most probably correspond to the solubilities in both the $\mathrm{Si}-\mathrm{Fe}$ and $\mathrm{Si}-\mathrm{Ni}$ systems. In the $\mathrm{Si}-\mathrm{Fe}$ system, the measured carbon solubility increased with increasing iron concentration, and the carbon solubilities reached $1.3 \mathrm{~mol} \%$ at $55 \mathrm{~mol} \% \mathrm{Fe}$ (SiC saturation) and $6.6 \mathrm{~mol} \%$ at $70 \mathrm{~mol} \% \mathrm{Fe}$ (graphite saturation). In contrast, for the $\mathrm{Si}-\mathrm{Ni}$ system, the measured carbon solubilities were small $(<0.14 \mathrm{~mol} \%)$ in the whole $\mathrm{SiC}$ saturation region, which are comparable with the carbon solubility in the silicon melt at $2053 \mathrm{~K}(0.094 \mathrm{~mol} \%)^{30)}$ The carbon solubility increased to $5.2 \mathrm{~mol} \%$ at $85 \mathrm{~mol} \% \mathrm{Ni}$ (graphite saturation).

\subsection{Carbon Solubility in the $\mathrm{Si}-\mathrm{Fe}-\mathrm{Cr}$ Alloy}

The measured carbon solubilities in the $\mathrm{Si}-(50-x) \mathrm{mol} \%$ $\mathrm{Fe}-x \mathrm{~mol} \% \mathrm{Cr}(x=0-40)$ alloys at $2073 \mathrm{~K}$ are shown in Fig. 5(a) together with the reported solubility in $\mathrm{Si}-50$ mol\% $\mathrm{Cr}^{11)}$ Note that the values correspond to the solubilities at $\mathrm{SiC}$ saturation in the quasi-ternary ( $\mathrm{Si}-50 \mathrm{~mol} \%$ $\mathrm{Fe})-(\mathrm{Si}-50 \mathrm{~mol} \% \mathrm{Cr})-\mathrm{SiC}$ system, as schematically shown in the figure. The measured carbon solubilities were greater than $0.14 \mathrm{~mol} \%$ in the $\mathrm{Si}-50 \mathrm{~mol} \% \mathrm{Ni}$ alloy and $1.0 \mathrm{~mol} \%$ in the $\mathrm{Si}-50 \mathrm{~mol} \% \mathrm{Fe}$ alloy, and increased to $3.9 \mathrm{~mol} \%$ with addition of chromium instead of iron. Here, the activ-

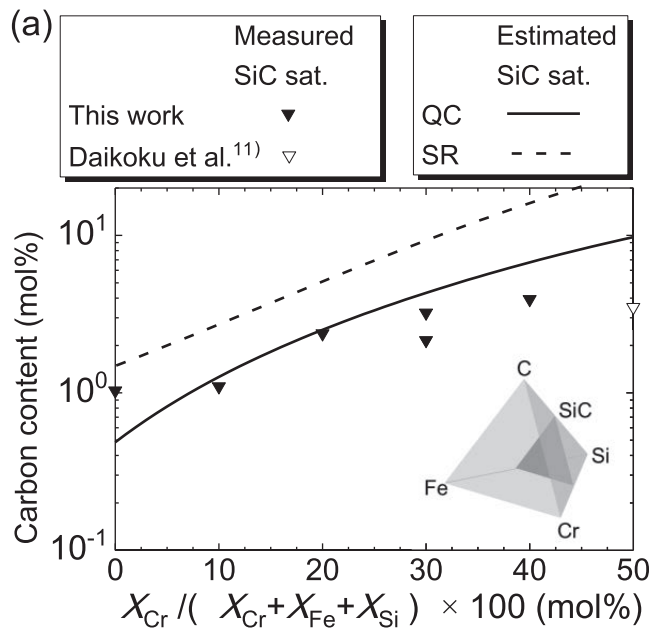

(b)

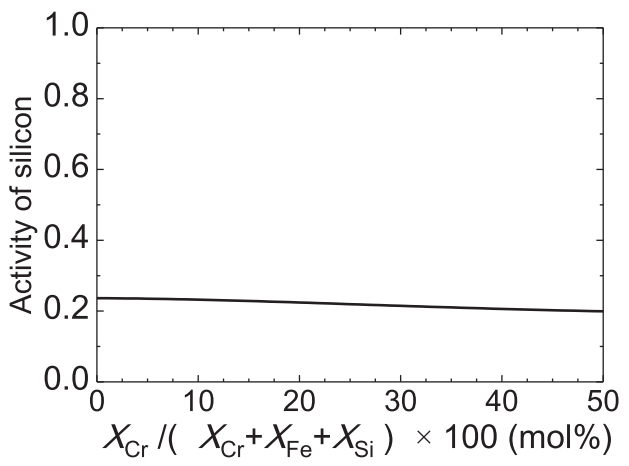

Fig. 5. (a) Measured and estimated carbon solubilities in the $\mathrm{Si}-$ $(50-x) \mathrm{mol} \% \mathrm{Fe}-x \mathrm{~mol} \% \mathrm{Cr}$ alloys at $2073 \mathrm{~K}$. The values correspond to the solubilities in the quasi-ternary ( $\mathrm{Si}-50$ $\mathrm{mol} \% \mathrm{Fe})-(\mathrm{Si}-50 \mathrm{~mol} \% \mathrm{Cr})-\mathrm{SiC}$ system, as schematically shown in the figure. (b) Estimated activity of silicon in $\mathrm{Si}-(50-x) \mathrm{mol} \% \mathrm{Fe}-x \mathrm{~mol} \% \mathrm{Cr}$ at $2073 \mathrm{~K}$.

ity of silicon in the quasi-binary $(\mathrm{Si}-50 \mathrm{~mol} \% \mathrm{Fe})-(\mathrm{Si}-50$ $\mathrm{mol} \% \mathrm{Cr}$ ) system determined using the thermodynamic data in Table 1 is almost the same over the entire composition range (Fig. 5(b)). This is because of the comparable strong exothermic mixing of the $\mathrm{Si}-\mathrm{Fe}$ and $\mathrm{Si}-\mathrm{Cr}$ systems (Fig. 4) along with the almost ideal mixing in the $\mathrm{Fe}-\mathrm{Cr}$ system. Therefore, the change in the carbon solubility in Fig. 5(a) mainly comes from the change in the activity coefficient of carbon of the alloy, which will be discussed in Section 3.4.

\subsection{Activity Coefficients of Carbon in the $\mathrm{Si}-\mathrm{Fe}$ and Si-Ni Alloys}

The activity coefficients of carbon in the $\mathrm{Si}-\mathrm{Fe}$ and $\mathrm{Si}-$ $\mathrm{Ni}$ alloys at $2073 \mathrm{~K}$ were determined from the measured carbon solubilities (Section 3.1) assuming equilibrium with either SiC or graphite (Eqs. (2) and (3)), and the results are shown in Figs. 6 and 7, respectively. The activity coefficient of carbon in molten silicon at $2073 \mathrm{~K}$ determined from its reported solubility ${ }^{30)}$ is shown as an open circle in each figure. In the case of $\mathrm{SiC}$ saturation, the activity of silicon in the liquid phase was determined from the Gibbs energy for mixing in the binary $\mathrm{Si}-\mathrm{Fe}$ or $\mathrm{Si}-\mathrm{Ni}$ alloy ${ }^{19,20)}$ at the same $X_{\mathrm{Si}} /\left(X_{\mathrm{Si}}+X_{\mathrm{Fe}}\right)$ or $X_{\mathrm{Si}} /\left(X_{\mathrm{Si}}+X_{\mathrm{Ni}}\right)$ fraction. In Figs. 6 and 7 , the maximum value for each composition is assumed to be more reliable in terms of the effect of $\mathrm{SiC}$ inclusions 


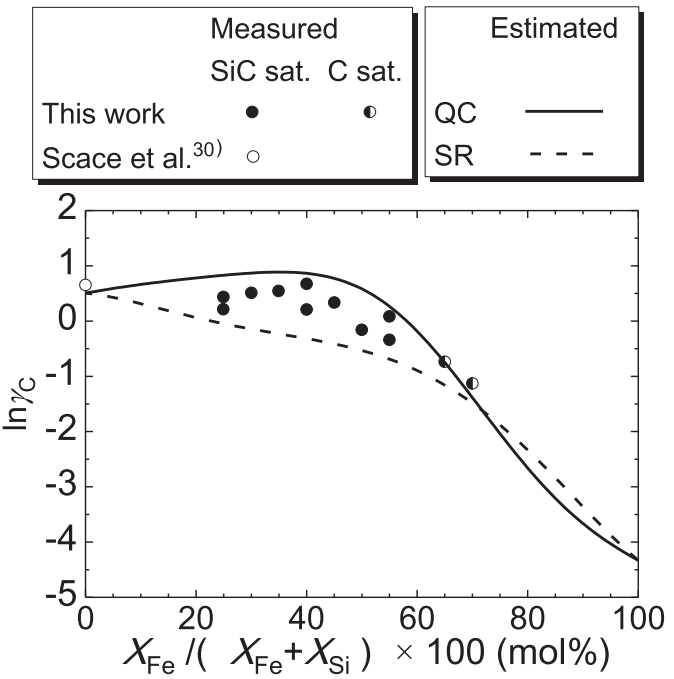

Fig. 6. Measured and estimated activity coefficients of carbon in the $\mathrm{Si}-\mathrm{Fe}$ alloys at $2073 \mathrm{~K}$. The largest value for each composition is assumed to be the activity coefficient of carbon.

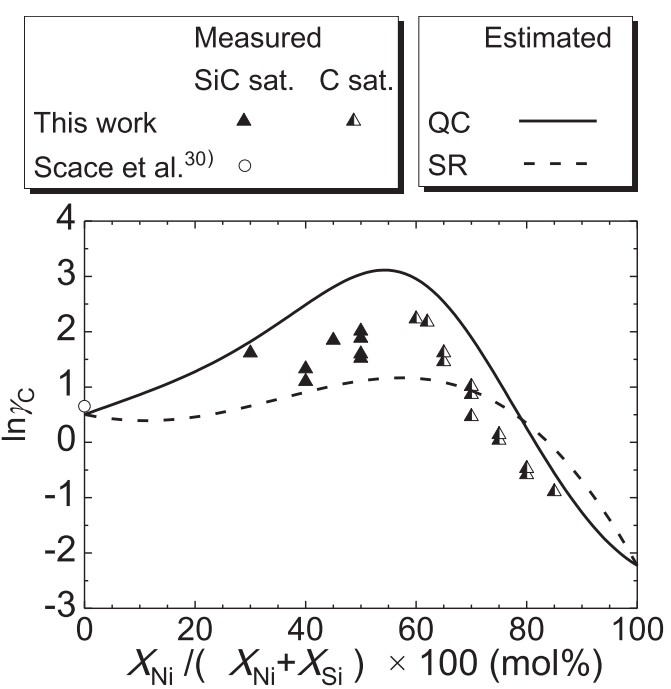

Fig. 7. Measured and estimated activity coefficients of carbon in the $\mathrm{Si}-\mathrm{Ni}$ alloys at $2073 \mathrm{~K}$. The largest value for each composition is assumed to be the activity coefficient of carbon.

described in Section 3.1, which was determined from the smallest values of the measured carbon content. For the $\mathrm{Si}-\mathrm{Fe}$ system, the obtained activity coefficient of carbon was almost constant for iron concentration less than $40 \mathrm{~mol} \%$, and it decreased at higher iron concentration (Fig. 6). For the $\mathrm{Si}-\mathrm{Ni}$ system, the activity coefficient of carbon slightly increased with increasing nickel content at less than 60 $\mathrm{mol} \% \mathrm{Ni}$, and it decreased above this concentration (Fig. 7).

In all of the systems, silicon has strong affinities with iron and nickel (Fig. 4), resulting in a repulsive interaction between carbon and the "solvent" alloy components. The activity coefficients of carbon in the alloys were compared with the values estimated by the sub-regular solution and quasi-chemical models. In Figs. 6 and 7, the estimated activity coefficients of carbon for the $\mathrm{Si}-\mathrm{Fe}$ and $\mathrm{Si}-\mathrm{Ni}$ systems determined by the sub-regular solution and quasi-chemical models are shown as dashed and solid curves, respectively. Note that the estimated values are the activity coefficients of carbon at infinite dilution, leading to some deviations from the real solutions, especially for iron concentration higher than $65 \mathrm{~mol} \%$ and nickel concentration higher than 85 mol\%, where the predicted carbon solubilities determined by the quasi-chemical model exceed $4 \mathrm{~mol} \%$. In $\mathrm{Fe}-\mathrm{C}$ system, Waseda et $_{\text {al. }}{ }^{23)}$ implied the existence of substitutional carbon atoms at $\mathrm{C}>12 \mathrm{~mol} \%$, and Yagi et al. ${ }^{31)}$ showed the difficulty in applicability of carbon behavior by the interstitial model at $\mathrm{C}>10 \mathrm{~mol} \%$. This suggests that the atomic site of carbon should be worth caring to when the quasichemical model is applied to predict the carbon behavior. In Fig. 6, for the sub-regular solution model, the activity coefficient of carbon for the $\mathrm{Si}-\mathrm{Fe}$ system continuously decreases with increasing iron. Conversely, the activity coefficient determined by the quasi-chemical model slightly increases with increasing iron addition to $40 \mathrm{~mol} \% \mathrm{Fe}$ and then rapidly decreases for higher iron concentration. For the $\mathrm{Si}-\mathrm{Ni}$ system, which exhibits more than $10000 \mathrm{~J} / \mathrm{mol}$ stronger exothermic mixing in the medium composition range than the $\mathrm{Si}-\mathrm{Fe}$ system (see Fig. 4), the activity coefficient of carbon values estimated by the quasi-chemical model in the medium composition range are larger than the measured values. The estimated value reaches more than 10 times that in pure silicon, and it then decreases with increasing nickel concentration. For the sub-regular solution model, there is not a significant increase in the activity coefficient and the activity coefficients are similar for $X_{\mathrm{Ni}} \leq 80 \mathrm{~mol} \%$. For both systems, the quasi-chemical model predicts a larger activity coefficient of carbon in the medium composition range and fairly well reproduces the values determined from the measured solubilities.

In Figs. 2 and 3, the solubilities estimated by the two models for the $\mathrm{Si}-\mathrm{Fe}$ and $\mathrm{Si}-\mathrm{Ni}$ systems are shown as dashed and solid curves, respectively. For both systems, the trends of the measured carbon solubilities are much closer to the estimations by the quasi-chemical model, although the estimated values are slightly lower than the measured values. In contrast, the sub-regular solution model seems to overestimate the carbon solubility. Consequently, the behavior of carbon in the $\mathrm{Si}-\mathrm{Fe}$ and $\mathrm{Si}-\mathrm{Ni}$ alloys is reproduced much better by the quasi-chemical model than by the sub-regular solution model.

\subsection{Activity Coefficient of Carbon for the $\mathrm{Si}-\mathrm{Fe}-\mathrm{Cr}$ Alloy}

The activity coefficients of carbon for $\mathrm{Si}-(50-x) \mathrm{mol} \%$ $\mathrm{Fe}-x \mathrm{~mol} \% \mathrm{Cr}(x=0-50)$ alloys at $2073 \mathrm{~K}$ and $\mathrm{SiC}$ saturation were also determined from the measured solubilities, and they are plotted against $X_{\mathrm{Cr}}$ in Fig. 8. Here, the standard Gibbs energy for $\mathrm{SiC}$ formation in Eq. (4) was used along with the activity of silicon determined from the Gibbs energy for mixing of the $\mathrm{Si}-\mathrm{Fe}-\mathrm{Cr}$ alloy ${ }^{17-19)}$ at the fixed composition ratio $X_{\mathrm{Si}} /\left(X_{\mathrm{Si}}+X_{\mathrm{Fe}}+X_{\mathrm{Cr}}\right)$. The activity coefficients of carbon at infinite dilution estimated by the sub-regular solution and quasi-chemical models are also shown by dashed and solid curves, respectively. The activity coefficient of carbon slightly decreases by replacing iron with chromium. Such a decreasing trend is observed for both models. In particular, the measured values are well reproduced by the quasi-chemical model for $X_{\mathrm{Cr}} \leq 30$ mol\%. Both models underestimate the measured values for 


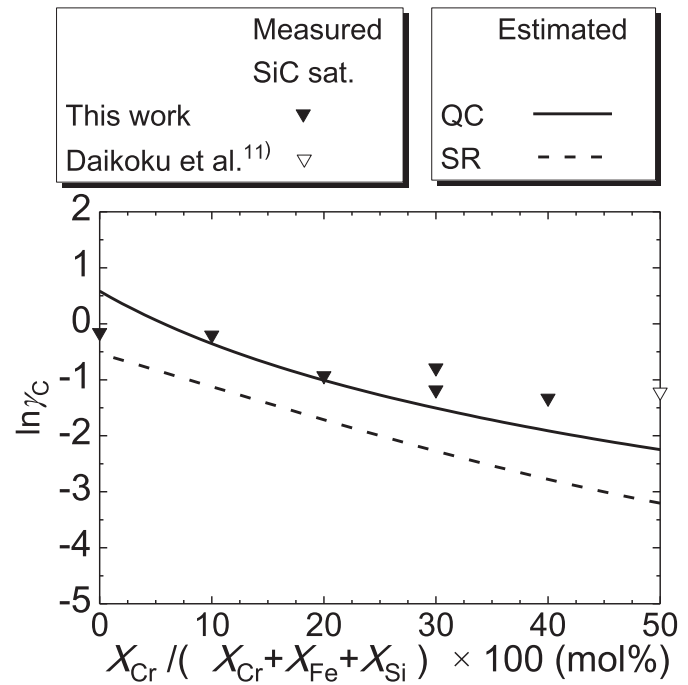

Fig. 8. Measured and estimated activity coefficients of carbon in the $\mathrm{Si}-(50-x) \mathrm{mol} \% \mathrm{Fe}-x \mathrm{~mol} \% \mathrm{Cr}$ alloys at $2073 \mathrm{~K}$.

$X_{\mathrm{Cr}} \geq 40 \mathrm{~mol} \%$, where the deviation from the dilute solution owing to the large carbon solubilities and the lower predicted silicon activity in the $\mathrm{Si}-\mathrm{Fe}-\mathrm{Cr}$ alloy than that in the alloy at $\mathrm{SiC}$ saturation presumably cause the difference from the measured values. The carbon solubilities in the $\mathrm{Si}-\mathrm{Fe}-\mathrm{Cr}$ alloys at $2073 \mathrm{~K}$ were also estimated by both models, and the results are shown in Fig. 5(a). The estimation by the quasi-chemical model (solid curve) agrees well with the measured solubilities for $X_{\mathrm{Cr}} \leq 30 \mathrm{~mol} \%$, where the estimated carbon solubility is smaller than $4 \mathrm{~mol} \%$, whereas it overestimates the measured solubility at higher chromium concentration. The sub-regular solution model overestimates the carbon solubility in the whole composition range, especially at high chromium concentration. This discrepancy is caused by the increase in the silicon activity with increasing chromium concentration at $\mathrm{SiC}$ saturation owing to its dissolution under the measurement conditions, while the estimation was performed for the composition of the quasi-binary $\mathrm{Si}-(50-x) \mathrm{mol} \% \mathrm{Fe}-x \mathrm{~mol} \% \mathrm{Cr}$ alloy, where the silicon activity decreases with increasing chromium concentration (Fig. 5(b)).

In summary, the behavior of carbon in $\mathrm{Si}$-based alloys for $X_{\mathrm{C}} \leq 4 \mathrm{~mol} \%$ can be well described by the quasi-chemical model with the available thermodynamic data for the binary constituents of the $\mathrm{Si}-\mathrm{Fe}, \mathrm{Si}-\mathrm{Ni}$, and $\mathrm{Si}-\mathrm{Fe}-\mathrm{Cr}$ alloys, as for the $\mathrm{Si}-\mathrm{Cr}$ alloy in previous work. ${ }^{11)}$ Thus, carbon acts as an interstitial atom and experiences a strong repulsive interaction owing to the attractive interaction of the solvent atoms in silicon-transition metal solvent alloys.

\section{Conclusions}

The carbon solubilities in molten $\mathrm{Si}-\mathrm{Fe}, \mathrm{Si}-\mathrm{Ni}$, and $\mathrm{Si}-$ $\mathrm{Cr}-\mathrm{Fe}$ alloys at either $\mathrm{SiC}$ or graphite saturation have been measured at $2073 \mathrm{~K}$, and the thermodynamic behavior was investigated using thermodynamic models. The results are summarized as follows:

(1) In the $\mathrm{Si}-\mathrm{Fe}$ system, the measured carbon solubilities at $\mathrm{SiC}$ saturation increased with increasing iron content, and the carbon solubility reached $1.3 \mathrm{~mol} \%$ at $X_{\mathrm{Fe}}=55$ mol\%. The alloy with $X_{\mathrm{Fe}}>60 \mathrm{~mol} \%$ was in equilibrium with graphite, and its carbon solubility was $6.6 \mathrm{~mol} \%$ at $X_{\mathrm{Fe}}=70 \mathrm{~mol} \%$.

(2) In the $\mathrm{Si}-\mathrm{Ni}$ system, the measured carbon solubilities at $\mathrm{SiC}$ saturation $\left(X_{\mathrm{Ni}} \leq 50 \mathrm{~mol} \%\right)$ were smaller than $0.14 \mathrm{~mol} \%$, which are comparable with the carbon solubility in molten silicon. At graphite saturation, the carbon solubility increased from $0.23 \mathrm{~mol} \%$ at $X_{\mathrm{Ni}}=60 \mathrm{~mol} \%$ to 5.2 $\mathrm{mol} \%$ at $X_{\mathrm{Ni}}=85 \mathrm{~mol} \%$.

(3) In the $\mathrm{Si}-(50-x) \mathrm{mol} \% \mathrm{Fe}-x \mathrm{~mol} \% \mathrm{Cr}$ system, the saturation phase was $\mathrm{SiC}$ over the whole composition range. The carbon solubility increased with increasing chromium concentration and was $3.9 \mathrm{~mol} \%$ at $X_{\mathrm{Cr}}=40 \mathrm{~mol} \%$.

(4) In all of the systems considered in this work, the trends of the carbon solubilities at less than $4 \mathrm{~mol} \%$ are reproduced by the quasi-chemical model, while the subregular solution model overestimates the solubilities. Thus, the quasi-chemical model is preferable to express the thermodynamic behavior of carbon in molten silicon-transition metal alloys.

\section{Acknowledgments}

This work was partly supported by JSPS KAKENHI (Grant Number 15H04166). We thank Edanz Group (www. edanzediting.com/ac) for editing a draft of this manuscript.

\section{REFERENCES}

1) C. Wagner: Thermodynamics of Alloys, Addison-Wesley, Cambridge, MA, (1952), 47.

2) K. Sanbongi and M. Ohtani: Bull. Res. Inst. Miner. Dress. Metall., Tohoku Univ., 11 (1955), 217.

3) E. T. Turkdogan, R. A. Hancock, S. I. Herlitz and J. Dentan: J. Iron Steel Inst., 183 (1956), 69.

4) F. Neumann, H. Schenck and W. Patterson: Giess. Techn. Wiss. Beih., 23 (1959), 1217.

5) T. Miki, F. Ishii and M. Hino: Mater. Trans., 44 (2003), 1817.

6) T. Miki and M. Hino: ISIJ Int., 44 (2004), 1800.

7) T. Miki and M. Hino: ISIJ Int., 45 (2005), 1848

8) M. Yonemoto, T. Miki and M. Hino: ISIJ Int., 48 (2008), 755.

9) L. S. Darken: Trans. Metall. Soc. AIME, 239 (1967), 80.

10) L. S. Darken: Trans. Metall. Soc. AIME, 239 (1967), 90.

11) H. Daikoku, S. Kawanishi and T. Yoshikawa: Mater. Trans., 58 (2017), 1434.

12) K. T. Jacob and C. B. Alcock: Acta Metall., 20 (1972), 221.

13) L. D. Teng, X. G. Lu, R. E. Aune and S. Seetharaman: Metall. Mater. Trans. A, 35 (2004), 3673.

14) P. Gustafson: Scand. J. Metall., 14 (1985), 259.

15) B. J. Lee: Calphad, 16 (1992), 121.

16) S. Kawanishi, T. Yoshikawa and T. Tanaka: Mater. Trans., 50 (2009), 806

17) B. J. Lee: Calphad, 17 (1993), 251.

18) C. A. Coughanowr, I. Ansara and H. L. Lukas: Calphad, 18 (1994), 125 .

19) R. Hultgren, P. D. Desai, D. T. Hawkins, M. Gleiser and K. K. Kelley: Selected Vales of the Thermodynamic Properties of Binary Alloys, ASM, Metals Park, OH, (1973), 231.

20) Y. Du and J. C. Schuster: Metall. Mater. Trans. A, 30 (1999), 2409.

21) A. T. Dinsdale: Calphad, 15 (1991), 317.

22) O. Kubaschewski, C. B. Alcock and P. J. Spencer: Materials Thermochemistry, 6th ed., Pergamon Press, New York, (1993), 308.

23) Y. Waseda, M. Tokuda and M. Ohtani: Tetsu-to-Hagané, 61 (1975), 54 (in Japanese).

24) H. Higuchi, K. Kimura, A. Mizuno, M. Watanabe, Y. Katayama and K. Kuribayashi: Meas. Sci. Technol., 16 (2005), 381.

25) Y. Kita, M. Zeze and Z. Morita: Trans. Iron Steel Inst. Jpn., 22 (1982), 571.

26) Y. Waseda and S. Tamaki: Philos. Mag., 32 (1975), 273

27) S. Otsuka: Trans. Jpn. Inst. Met., 26 (1985), 167.

28) M. L. Saboungi, P. Cerisier and M. Blander: Metall. Trans. B, 13 (1982), 429

29) S. Banya, T. Azagami, Y. Iguchi, A. Kikuchi, K. Sugimoto and T. Yamamura: Physical Chemistry of Metals, Vol. 1, The Japan Institute of Metals, Sendai, (1996), 9 (in Japanese).

$30)$ R. I. Scace and G. A. Slack: J. Chem. Phys., 30 (1959), 1551.

31) T. Yagi and Y. Ono: Tetsu-to-Hagané, 49 (1963), 133 (in Japanese). 